\title{
RHYTHMIC MUSIC PEDAGOGY: A SCANDINAVIAN APPROACH TO MUSIC EDUCATION
}

\begin{abstract}
Rhythmic music pedagogy is a relatively new Scandinavian approach to classroom music education that offers a variety of methods and strategies for teaching and learning music, especially within the performance of improvised and rhythmic music. This article is based on two earlier projects published in Norwegian, in which the concept of rytmisk musikkpedagogikk (or "rhythmic music pedagogy") as well as its applications and implications were thoroughly described. This research confirms that rhythmic music pedagogy may be an effective strategy for learning music in general, but most especially for learning skills associated with ensemble musicianship and playing by ear. In a multicultural and fluid society in which there are tendencies toward passivity and fragmentation, it may be more important than ever to maintain the idea of music as a collaborative creative process that extends across borders; in this context, rhythmic music pedagogy can play a central role in children's social development. As a social medium, ensemble playing requires the participant to decentralize socially, since the perspectives of the other participants are necessary for a successful performance. The activity's general potential for re-structuring social settings and moving boundaries in a positive way should not be underestimated.
\end{abstract}

Keywords: rhythmic music pedagogy, ensembles, playing by ear, embodiment, improvisation, teacher challenges, Scandinavia

\section{INTRODUCTION}

What assumptions do international music educators have regarding music education in Scandinavian schools? What is known concerning music teaching in Norway - specifically the practices of Norwegian music teachers - and what may others learn from the current situation in Norway?

The study plans for music in compulsory basic school education in Norway have gradually changed over the last few decades. Musical activities - making music together, dancing, improvising and composing - have increasingly been given more focus and attention. Most primary and secondary school education in Norway is governed and financed by the State of Norway, and there is a national curriculum. In the most recent curriculum, K06 or Kunnskapsløftet (2006), music improvisation as an activity has become dominant at all levels. At the lower secondary level, the concept of samspill - playing together in a cooperative ensemble - or cooperformance as we may call it, has become a core activity. From 1997 until 2002, the author was the leader of a research project, the overall aim of which was to explore and describe the concept and practices of rytmisk musikkpedagogikk or rhythmic music pedagogy (RMP) - a relatively new educational movement in Norway at the time. The concept had not previously been researched, so the primary purpose of this project was to investigate and discuss its meaning with some music colleagues interested in rhythmic music pedagogy, all graduates of Bergen University College who were working in the 
primary and lower secondary schools of Bergen, Norway's second largest city. Our preliminary understanding of the concept was that it might allow teachers to engage pupils in the excitement of rhythmic ensemble playing independent of their skill in reading music notation. We were all fascinated by the possibilities that this special way of working with playing by ear appeared to offer. The project has been described elsewhere in Norwegian, and published in a film/video, a book and a CD (Hauge, 1999; Hauge \& Christophersen, 2000; Hauge \& Hungnes, 2002). A few years later another project was carried out, a case study with observations and interviews of a "rhythmic" music teacher which went into some depth on her role and the challenges she faced as a teacher in the classroom, and focused on her personal reflections regarding her teaching (Hauge in Olsen \& Stenersen Hovdenak, 2007).

\section{THE AIM OF THE STUDY}

To provide knowledge of rhythmic music pedagogy as a relatively new Scandinavian educational concept and approach, to have it described as clearly as possible and to identify, explore and discuss some of the didactical implications and applications within a Norwegian public compulsory school context.

\section{MATERIALS AND METHODS}

The research question of the first project was: What is "rhythmic music pedagogy"? How do we understand this concept and what are its implications? What are the basic concepts; and to what extent and in what ways can these ideas be implemented within the compulsory school framework? What are the criteria for choosing material, activity and working methods? The research methods used were observations, interviews and analysis of journals and video recordings. Four carefully selected "rhythmic" music teachers were followed and observed working at different schools in Bergen for an entire semester. At the primary and lower secondary levels in Norway, the subject music is allotted one or two 45-minute lessons per week, and for one semester teachers' lessons, were video recorded producing a total of 26 hours of filmed data. In addition to being observed and video recorded during their lessons, the teachers also were challenged through interviews to reflect upon their own teaching and relate to the general research questions. Every teacher also kept a journal, and their writings were distributed to the entire group. It served the purpose of sharing plans, activities and evaluations. Project meetings were organized as often as possible during the whole year of field work - in the first months once a week, later it was reduced to every other week or once a month. Very little has been published in English regarding the Scandinavian concept of "rhythmic music pedagogy," which is surprising considering how widespread the notion of "rhythmic music" has become in schools of Norway, Denmark, and Sweden across recent decades. Based on a background of research previously published in Norwegian, this article has three objectives: (1) to thoroughly explore the concept of "rhythmic music pedagogy" and examine how it is commonly applied in school music teaching in Scandinavia, (2) to offer detailed analysis of a particular approach to "rhythmic music pedagogy" that has been popularized in Norway, and (3) to report on the findings from a case study of a Norwegian music teacher who uses this approach.

\section{Rhythmic music pedagogy - the label versus the concept}

The label rhythmic music pedagogy was first used in 1992-1993 by jazz musician and pedagogue Knut Kristiansen for a 30 ECTS music course at the Music Department of Bergen University College. This course ran for two years and was very successful, but was dropped due to financial restraints and a shift in priorities at the institution. As a sensor at the examinations for this course, professor Even Ruud became acquainted with the concept, and he was the first to try 
to describe the Bergen approach from the "outside". He considered it to be pedagogy based on the inner hearing - gehørpedagogikk - connected to a core pulse in the body. This combination was expressed in a single concept that seemed to encourage the pupils' interest in creating music together (Ruud, 1996, $108 \mathrm{f}$ ). He observed the useful and popular working methods frequently applied by the students in their presentations in these practical examinations. This gave rise to questions: Wasn't the concept more than these useful working tools? Wasn't it a part of a wider cultural movement or ideology within music pedagogy? For the five members of the project, there were obvious connections to radical cultural movements in Denmark, particularly to musicians, pedagogues, schools and cultural organizations such as Leif Falk, a music teacher at Århus Friskole and the Center for Rhythmic Music and Movement at the Music Conservatory in Århus; "The rhythmic evening school" and the Rhythmic Music Conservatory in Copenhagen; the Danish organization of jazz musicians and the Consultancy for Rhythmic Music Education. While the use of terminology may differ, the basic ideas are much the same (Hauge \& Christophersen, 2000, 20-21). In Bergen, however, authors wanted to explore these connections and also describe the concept in more detail in our writings, seeking to adapt the ideas to a compulsory school context, as well as to provide concrete examples of practice.

\section{Rhythmic music versus rhythmic music pedagogy}

All music is rhythmic, no doubt, but when one talks about rhythmic music one usually refers to some specific music styles and traditions - music with roots in an Afro-American tradition. According to the Swedish professor Bertil Sundin, who was one of the first to use the concept, it is not just music played by Afro-Americans but may also include popular genres such as pop, rock, jazz, reggae, hip hop, salsa and samba (Sundin, 1988, 62-63). Music pedagogue Aage Hagen at Rhythmic Music Conservatory in Copenhagen confirmed this interpretation a few years later, stating that in Denmark it is the general label encompassing the many styles within vernacular music that have appeared in the last century, including folk music or world music to a certain degree (Hagen, 1996, 69). He mentions some specific genres in addition to those mentioned, including styles like blues, rhythm \& blues, rock'n roll, soul, funk, country and European rock.

Rhythmic music has also become a common label and concept in Norway, and is discussed widely, even in governmental publications. In Stortingsmelding number 21, 2007-2008, Samspill. Et løft for rytmisk musikk the definition of rhythmic music includes "pop/rock, folk music, world music, and jazz and existing genres under these and mixed genres. Included is also blues and ballad singing" (Stortingsmelding, 2008). Note that this definition, promoted by the Norwegian government, is broader than the definitions by Sundin and Hagen, including folk music without limitations. Catharina Christophersen discusses the label in great detail within her doctoral thesis, and like Hagen she identified underlying political motivations for defining "rhythmic music" as an artistic entity that merits governmental recognition. She points to the fact that it is a quite imprecise concept; however, since it is widely used and accepted, one feels obligated to find meaningful ways to use this popular terminology (Christophersen, 2009, 24-26).

In their article World beat David Hebert and Patricia Shehan Campbell introduce and describe the concept world beat. They describe it as the early fusion that transpired when the roots of African music met rock (Campbell \& Hebert, 2011, 113). World beat embraces nearly any style and is especially keyed to the blend of popular music with folk and roots music of the African continent and across Latin America. World beat can appear anywhere - as a musical phenomenon that adds a decided "groove" (and often Western rock instruments) to music that nonetheless is "folk", rustic, rural, or traditional in character. World beat transcends genre 
names in that the blend of pop with folk influences is often unnamed but decidedly present. The concept is characterized as a sign of the time, a result of the world that is connected by telecommunication that brings people from all corners of the world in touch with one another, at which point influences combine to make for new artistic expressions. This concept has a more restricted meaning than the Norwegian concept of rhythmic music focusing more on the African roots, the fusion of African roots with rock, not including any kind of rhythmic music. At the same time as it gives restrictions it still is open for the creative ideas and working strategies of rhythmic music pedagogy, a broader educational concept representing some fundamental ideas related to music and humankind, especially the idea of music as samspill - as cooperformance (cooperative improvisation) and embodying the music.

\section{The core of rhythmic music pedagogy (RMP) - the changing musical context}

The function and the role of music have changed across history, which provides an impetus for the development of RMP. In order to experience music in earlier times, the music itself had to be located within contexts that one could easily identify - with relation to time, space and social situation. In order to experience music at all, there had to be someone in the room, or at least within a certain geographical distance, who could perform. In addition, music was very often directly connected to social life - to human rituals and relations, and to everyday use and functions (Small, 1983a, b; Small, 2010). Today the situation is different. The technological revolution has made music from all times and places available everywhere on the globe at any time. Sundin has made the point that already in the seventies most children who started school in Sweden had probably heard more music in their short lives than their great-grandparents had during their entire lives (Sundin, 1995, 9). The amount of music children have access to has not declined since then; today we also have internet, DVD, Mp3, iPhones etc.

Whether this access to huge amounts of music from all times and places has developed a more positive relation to music is a relevant question. At the same time as old borderlines and distances have disappeared, new ones have been created. Media music is not necessarily a phenomenon that brings people together; it can also contribute to maintaining or even enhancing differences and distinctions. In spite of the fact that there is more music available and music courses than ever before, there seem to be a growing number of people who define themselves as "non-musical". Singing, dancing or playing an instrument are no longer a part of their natural expressional repertoire. Instead of being an active and visible part of everyday social life and of celebrations, music has taken on a more unclear and complex role and function. Listening, rather than singing, dancing and playing has become more important for most people, but this listening is very often passive - in the background of other events or activities.

\section{Music as a social activity}

The idea of music as something people actually do together in a particular situational context - music as an activity rather than a collection of works - is the core idea in RMP. Music is viewed as a means of artistic expression, and communication is the main purpose. Music performance - singing, dancing and playing - has its own value as a means of expression. The first time the author encountered this idea was when Christopher Small visited Bergen University College in the beginning of the 1980s. In the lecture he gave and also in his book Performance as Ritual Small (1983) described his philosophy and stressed how human beings, not just professional musicians, have a need to develop their inherent musical abilities and resources and the potential to do so. As human beings, people are created to use their inherent capacities; they should use their fantasy and creativity actively and not simply be consumers. According to Small (1983), 
the opportunity to develop natural, inherent talent should be a universal human right. In schools, this can be achieved through creative rhythmic activities and ensemble playing by ear; the pupils can also develop basic knowledge and skills in music. Given the tendencies toward passivity and fragmentation that we have in our modern society today, the idea of doing and developing something together across borders (e.g., cultures, religions, abilities) may be more important than ever. Compulsory school has a key role to play in this development; it may be the most prominent social setting in our society, and music can be a "qualified tool for re-organizing social settings, moving boundaries" (Ruud, 1997, 106). The potential of music to activate, raise consciousness and create positive common social arenas should not be underestimated. It is of vital importance that we develop an understanding of the role and the meaning music can have for the individual and for society; however this implies the need to develop a fundamental understanding of music as art and craft.

\section{The body as an instrument - embodying the music}

In this section the main points will be described from what the author believes to be the only major textbook for the teaching of rhythmic music pedagogy in Scandinavian schools (Hauge \& Christophersen, 2000). This RMP method was originally pioneered at the largest program for music teacher education in Norway. According to this method, which has been widely used now for over a decade, a feeling of pulse, swing and groove are all very basic ingredients in rhythmic ensemble playing. These ingredients must become so integral to the playing that they are an organic part of the music across the group. In his book Mit Motiv (Christensen,1983, 55), Bernhard Christensen suggests an explanation of these fundamental qualities in terms of a distinction between two kinds of rhythm; one is denoted by capitals (RHYTHM) and the other by lower-case (rhythm). For a musician, it is easy to recognize the former, which is an organic kind of rhythm that is considered valuable. However, since his second category is rather vague, the author does not consider this distinction very useful. It is difficult to describe quality in music with words. In rhythmic music, the question is, however, how to make the rhythm (and the music in general) become so embodied and integrated in a group of ordinary pupils that they really play together and get the music to "swing" or "groove", thereby ensuring that the musical experience becomes a "peak experience".

Everyone can learn to play the drum and other percussion instruments at a basic level. With a little help, most pupils can master simple drum patterns and play rhythmic grooves in a rhythmic ensemble within just a few lessons. Congas and djembes have great potential as ensemble instruments, since they have a good sound and provide an opportunity to practice the coordination between right and left hands which is basic with many instruments. With small variations in playing - open strokes, muffled strokes, slap strokes - these can be played along with other percussion instruments and create a basic repertoire of grooves covering a broad spectrum of styles. At the lowest levels in school, the teacher can use the conga or djembe her - or himself to accompany and support the children in the imitation and improvisation games that accompany other music activities. The development of coordination skills is a goal rather than a prerequisite for participation. At the higher levels pupils can work with several percussion instruments and/ or other instruments such as piano, guitar and bass to produce arrangements with more complex grooves to accompany the singing, dancing, solo playing and improvising of the group.

To develop basic rhythmic ensemble skills, one can use several methods. Most of these include voice and body; basic steps, rhythm phonetics, word rhythms and other types of ostinatos with voice and body are some of the tools used. Basic steps in RMP are periodic movement 
patterns of two or more steps derived from the style of music one is working with. The steps should be so simple that anyone has a chance to master them. Their main function is to keep the activity and circle together. Using basic steps, it is possible to give the music and the rhythm a visual and embodied expression. By including more senses and using patterns where each step has a certain role related to the music, it is possible to gain a more concrete reference. Both the leader and participants can recognize visually when everyone is locked into the groove. Even if something is not deeply understood, this phenomenon can be clearly seen. Another function of the basic steps is to produce energy across the group. The movements should be performed in the best way possible in order to develop the maximal artistic energy. In this process, the RMP leader plays a crucial function as a model for both sound and movement.

A popular and useful basic step in RMP is the so-called universal ethnic step. This is a pattern that is very common in many music cultures around the world - not only African cultures but also Asian, Latin American and European. It can be used as a repeated basic foot movement pattern for 2-measure phrases of music in 4/4, 12/8 or 6/8 time. The movement has four steps: (1) right foot forward one step on the count of $1,(2)$ left foot one step in its initial place on the count of 2, (3) right foot backward one step from its initial place on the count of 3, and (4) left foot one step in its initial place on the count of 4 . The subdivisions can be marked by a slight swing of the body ( 1 and 2 and 3 and $4 \underline{\text { and }}$ ). The same steps can be used for 12/8 time but the feeling is different since there are three subdivisions ( 1 and a 2 and a 3 and a 4 and a). Other patterns include steps from side to side (4/4 and 12/8) and triangle steps (3/4 and 9/8). These dance steps can be used as a basis for improvisation or for developing a more sophisticated choreography (Hauge \& Christophersen, 2000, 139-141, or video Hauge, 1999).

Rhythm phonetics is a system of phonetic human voice sounds that try to imitate the percussion instruments and their sound in a band context, as used in RMP. On a djembe or a conga, you may have different kinds of strokes in a rhythmic pattern; for example, making dark and light sounds, sharp and soft sounds, and long and short. Using their voices, musicians imitate these different strokes, so they sound like the instrument. An imitation of a djembe playing "Afro Hip Hop" might become: Dung dung bak du geng ge dung bak (Hauge \& Christophersen, 2000, 154, or Hauge \& Hungnes, 2002) (see Picture 1).

Picture 1. Afro Hip Hop

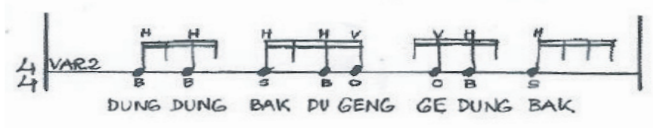

An imitation of congas playing the Son Montuno rhythm in the Cuban music tradition might become Du ga ba ga du ga ba gong, Du ga ba gogong ba gu ging (Sulsbrück, 1999, 80, also performed at the CD included). It is impossible, of course, to demonstrate how rhythm phonetics works in an article. Nevertheless, it is important to stress the fundamental role of the teacher, as an artist and performer, providing an inspiring model for the pupils - putting energy into the activity.

Word rhythms are patterns constructed using words, which can be a very useful pedagogical tool for training rhythmic skills, especially at the lowest levels in school. Word rhythms can be spoken responses in a conversation or a story, and together they can form a 
spoken chorus. The word rhythms can be taken from songs and rhymes, and can be adapted and used as an accompaniment to a song or a poem; they can be either single patterns or a combination of different rhythmic patterns in a more complex groove. Word rhythms can be used as building blocks in more complex arrangements with other ostinatos or patterns, as well as for making simple melodies. På karneval, på karneval (translated: at the carnival) can serve as the Norwegian word rhythm for the surdo drum in a samba groove (Hauge \& Christophersen, 2000, 158).

At the lowest levels in Primary school, fiction or story can provide a good frame for developing these skills. Within a thematic frame, a rhythmic groove can develop into a whole story or drama. One of the teachers in author's 1997 project used a class tour up a local mountain in Bergen as a frame. He created a story with speech lines included in the story. "Vi tar Fløibanen, vi tar Fløibanen" (translated: We take the Fløien cablecar) or "Håh, bare vent å se!" (translated: Ho, just wait and see!). Rhythmical blinking, winking and groaning were also included in this play (Hauge \& Christophersen, 2000, 148-149).

A teacher should not underestimate the motivation and endurance children have when it comes to practicing skills in music. On the one hand, one would think that the activity in itself is motivating - that children are generally interested in developing performance skills in playing, singing and dancing; and that they can also see the need for practice. On the other hand, we know that pupils are very different, that developing skills is something that takes time, and that the teacher must provide some variation. By including a broad variety of activities and meeting the children's need to play and use their fantasy, a teacher may be able to keep the attention of the group a little longer than otherwise.

Ostinatos are in general very well suited to creative ensemble playing, and are commonly used in the RMP approach. Ostinato is an ancient technique for creating music, which became a very popular pedagogical tool with the advent of Carl Orff and his Orff Schulewerk-concept. Ostinato refers to a rhythmic, melodic or harmonic pattern that is repeated throughout the music. They may differ in length. Melodic ostinatos can be sung by the pupils, and may therefore lay a good foundation for the introduction of melodic instruments. Several ostinatos can be put together and the whole band can be performed using voice and body before the real instruments are introduced and the pupils are given their actual roles.

Rhythms you can sing or perform with your voice and body are rhythms you have perceived and understood. Rhythm phonetics and word rhythms that are performed vocally, in combination with some simple basic steps, can be an important support in the introduction and development of a new rhythmic groove. The rhythmic patterns or ostinatos can also be performed bodily by slapping, clapping, etc. A group that is able to perform a complex percussion groove using body and voice should be well prepared to transfer the groove to percussion instruments.

\section{From parallel activity to different roles and parts}

In parallel activity, everyone is doing the same activity and following the same rhythm, melody or movement pattern; everyone is imitating the leader. In contrast, in an RMP ensemble there are usually several roles and parts with different tasks or patterns; some sing, some play, some dance and some improvise. Within the accompanying rhythmic groove, there may also be different musical patterns performed on different instruments.

The coordination of different roles and patterns so they fit perfectly is a great challenge for everyone in the ensemble. No role or part functions independently, since they gain their importance in the co-playing with the others. In an ensemble, everyone depends on everyone else - there 
and then. Since ensemble music exists only in the moment, it is very vulnerable. Thus, a basic understanding for the challenges connected to ensemble playing in general and to the different roles and parts being performed in particular, the individual musicians develop.

\section{Rotation as a tool for better playing}

Rotation refers to the switching on roles and parts, and in the classroom context this may be a good tool both for introducing more democracy in the classroom, and for improving the quality of the music - in the RMP ensemble playing. Rotation can be used as a tool which can help pupils become more familiar with the musical ingredients and develop each participant's rhythm, coordination and musical independence. This method allows everyone to first perform all the individual parts in a groove by setting up parallel body/vocal percussion activities through which participants rotate. Only later are the various parts gradually combined, with the participants taking different roles - first two, then three, four, etc. - and try out the combinations. Thus, when the roles and instruments are assigned, everyone will have a better understanding of the challenges involve an example of rotation can be seen when rhythmic drum patterns are being practiced in the classroom with only a few drums. Some pupils can use the drums while the rest of the class can use their bodies as instruments; the drums can be passed around. By using the thighs as drums, pupils can practice the use of left and right hand and coordinate the different movements involved, before it is their turn to use the real drum. When it is their turn to play the drum, they already have some skills. Body percussion can also provide a great accompaniment for work with improvisation on the drum.

\section{Improvisation}

To improvise involves creating your own musical expressions in the moment - then and there. In a RMP group context it also implies cooperation between the individual and the group. As a classroom activity, improvisation opens up many possibilities. The personal engagement demanded of the participants can have a favorable impact on general learning and development. In addition, improvisation can contribute to the variation in activities; it makes room for all levels of performance skills and can thus be a good way of working with music.

In the context of music, "improvisation" is not a label with which teachers and pupils are immediately comfortable. In the minds of most people, musical improvisation is associated with musicians who are experienced or professional - who are jazz musicians or have a certain standard of performance technique. Nothing is as personal as singing, dancing or playing a solo while others watch or listen. The risk of being judged to be inadequate is present.

However, improvisation may also be a working method, a way to work with music. One should also remember that improvisation is an important element in folk music and dance all around in the world. In some music cultures, improvisation is at the core of the tradition. In classical European music tradition, we have to go back several centuries to find the great improvisers.

Improvisation is something we do all the time in our daily lives, and children improvise when they play. It can be regarded as a sort of play, playing with sound. One characteristic of children's play is that it is unpredictable and only controlled by the participants; it allows for spontaneous behavior and choices. The incisions and judgments made by the participants are of decisive importance for the ongoing process. If we go back several hundred years in Norway, the word for play ("leik") also referred to improvising on instruments. In the nineteen seventies, the English composer John Paynter (1970) wanted to open up the concept of music by introducing the idea of sound painting. His reference at that time was the so called "new music" 
in which composers use all kinds of sounds in their compositions. These compositions challenged the performer to improvise. Paynter's Sound and Silence: Classroom projects in Creative Music" (1970) was later translated into Norwegian and the ideas developed there have had an important impact on the conceptualization of music education in Norway. Through imitation and improvisation, children can gradually pick up the codes of their own musical culture. Parents and pedagogues can support this process in various ways. The inclusion of improvisation at school via RMP gives pupils the opportunity to adapt musical impulses; thus, improvisation may be an important tool for developing fundamental musical competence.

\section{Improvisation frames}

The concepts of rammesang and rammelek have also been borrowed from Denmark in the RMP approach. Søren Hedegaard defines these as strategies for musical collaboration involving children. Translated literally, rammesang is frame-song and these songs serve to inspire the initiatives and the development of ideas related to play with music, and to singing, dancing and playing instruments with small children (Hedegaard, 1995, 95).

A frame-song is a point of departure, not an end in itself. It is first when the improvisation activity has started that the song has its value. The primary function is to create an inspiring and supportive frame around the improvisation. This is done by switching constantly between imitation and improvisation, between questions and answers, and between repetitive refrains or accompaniments for everyone and open "rooms" for solo improvisation. These rooms can be in the beginning of a song, after the song or in the middle; and can also be inserted between the verses of a song.

Translated directly, rammelek means frame-play and has the same function as frame-song including rhymes, poetry, rhythmic verses and other kinds of frames without melodies - offering different ways of organizing the improvisation. If they are focusing the play or the game, children forget to be nervous when they improvise. For concrete examples with frame-songs and frameplays, listen to the CD Kotokaka (Hauge \& Hungnes, 2002) or observe the teachers working in the video (Hauge, 1999) (see Picture 2).

Picture 2. Are you Tough?

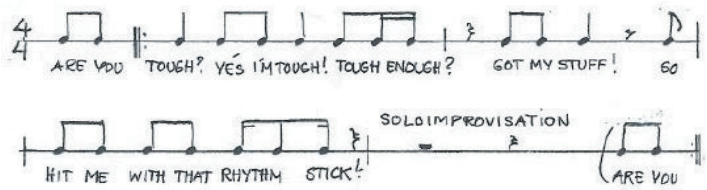

In addition to creating a frame around improvisation, singing or other vocal activities can be the actual content. Scat-singing is a concept that was introduced by Louis Armstrong and Cab Calloway in the 1920's. This term refers to a way of singing in which the voice is used as an instrument, producing phonetic sounds instead of text, and imitating trumpets and other solo instruments. Scat-singing can be used at all levels in school with shorter improvisation rooms for the new pupils and longer for the more experienced. Work with frame-songs and rhythm phonetics may be a good introduction to scat-singing.

Break refers to places in the music where the musician tries to create a break; for example, a tension, a contrast, a surprise, a passage, a link or a rounding off. Depending on the musical style and the function of the break, it may differ in structure and position in the music. The break 
may be as simple as a sudden pause in the groove for some bars, or as complex as a contrastive way of playing.

A break can have a gathering and intensifying function. In a groove, the players have different roles and tasks. In the break, the attention and energy is directed to one particular instrument or one particular rhythmic pattern, and this can be very effective. Breaks can be improvised or agreed upon. The working strategy for improvising breaks is the same as for frame-songs; a room of a couple bars that everyone is familiar with has to be established and then the soloist can improvise within this frame. These rhythmic patterns can be imitated by the whole group, adding some extra bars.

Once a rhythmic groove, some basic steps and a break have been established, one can also work with dance and movement improvisation. The rhythmic performance of improvised simple movements can become patterns that are imitated, and even repeated and transformed into a choreographed dance steps for a group while the rest of the class is playing the groove. A percussion break can also have choreographed movements. A couple bars, perhaps within the frames of a frame-song, could be the length of the improvisation initially. At the lower levels, the movement patterns of animals or fantasy and fairytale figures can be used. A groove on percussion instruments can accompany the movements. An example will be provided at the end of the next section.

\section{Layering in or out-group improvisation}

When everyone in a RMP group or a class is involved in creating and sculpturing music by improvising, we usually consider this group improvisation. One method used to achieve this is "Layering in or out". The concept is old, but the term is borrowed from Arthur Hull's Drum Circle Facilitation $(2006,73)$. As a point of departure, a leader and some individual players are sitting or standing in a circle. A pulse or a beat is given, and then the leader adds players according to some kind of system; for example, this could be done simply by adding players following the circle, or by adding specific types of instruments. When everyone has joined in the playing, instruments may then be subtracted. The players can also be subtracted by different systems; for example, individually or by category. The leader can thus sculpt the music according to his or her ideas. For example: start at zero and add players one by one until everyone is playing; subtract everyone except those playing the low drums; add everyone at the same time at a certain signal; subtract everyone except those playing the high drums; add everyone again; and finally, subtract players one by one until there is only one player left. Visual signals indicating addition and subtraction must be agreed upon with the leader in advance. A break can also be agreed upon and have a great effect. Drums are very suitable for this kind of group improvisation, as are smaller percussion instruments. Body and vocal percussion can also be used. It is a good idea to have a strong pulse, using basic steps as a frame. All kinds of vocal sounds can be used - rhythm phonetics, nonsense words and scat-singing. As mentioned, games, stories and fiction can be useful tools in working with improvisation at the lower levels in school. For example, in the game The Successors of the King, the King is the leader of the group improvisation. A simple movement pattern is created by the King and this special way of walking or moving will be the frame for the improvisation. The movements of the King can take place on the inside of the circle or outside. When everyone is playing, and a groove has been established, the King can subtract players by giving these players a particular signal. The subtracted player then gets up and imitates the walk or movements of the King instead - forming a line behind the King. When the King is happy with the groove of the remaining group of players and with the way the others are copying 
his movements, he can either add a short improvised melodic pattern that the others imitate with their voices; or he can give the signal to stop, and then he, and his followers, can go and select their favorite instruments that are now available. There is always one instrument too few and the child without an instrument becomes the new King and leader - and with the new leader there is also a new walk or movement pattern and a new accompaniment/groove.

\section{Making one's own composition}

Learning to improvise is a basic activity in rhythmic music pedagogy, and should be a center of focus. Improvisation should be used as a working method for exploring and developing musical and personal ability, and can also be used as a way to practice composition. An improvised group rhythm can be sculptured in many different ways and be used as a point of departure for creating a whole arrangement. The resultant groove can be used as an accompaniment for other instruments, as an accompaniment for a melody, a solo or a text, and as arrangement with choreographed movements and with "introes", "outroes", breaks etc. Improvised vocal ostinatos can grow into the refrain of a song; short improvised movement patterns can become a choreographed dance. What is the difference between improvising and composing? The dividing line may be hard to see sometimes. Many would say that composition involves a larger degree of mental activity, and that the music is usually fixed before it is played. While the composer can go back and forth and make judgments and changes throughout the composition process, the player does not change the composition once it is finished. Nevertheless, some music invites or even demands improvisation and it is only the frames that are stable. In improvisation one usually says that the music is created in the moment, then and there. Like compositions, improvisations can be planned and involve a high degree mental activity, in the sense that the player has an idea about how to sculpt his or her playing. The main difference is that the performer who improvises has a certain freedom to choose within the frames in the actual moment of performance.

\section{Challenges for a "rhythmic" teacher in a compulsory school framework context - research outline for the second project}

The research question in the second project was: What implications does playing by ear in an ensemble "cooperformance" have for the teacher role at the compulsory school level? What are the particular teacher challenges for a "rhythmic" approach in a compulsory school framework context?

In the second project author wanted to focus more in depth on the teacher's role in the RMP approach. It was chosen to have a case study of one particular "rhythmic" teacher and address her own reflection on her own teaching more deeply. The teacher chosen, "Hilde", was an experienced teacher, and she taught music in all classes at the lower secondary level in a compulsory school outside Bergen. To obtain relevant data, the qualitative interview approach was used as described by Steinar Kvale (Kvale, 2005). Interview questions were: 1. Which goals do you have for your classes? What ultimately do you want to achieve? 2. Which factors have an impact on the selection of course content and working methods? 3. How are the lessons organized and the plan implemented? 4. How do you view your own role as a teacher? 5. How do you evaluate the results of your own teaching? 6. Which type of problems or challenges do you meet and how do you try to solve them?

All answers from the interviews with "Hilde" were recorded, and the author also observed her classes to see if there was correspondence between her words and actions, so the methodology was based on the "geographic" method described in Doing qualitative research: Circles within circles (Ely et al., 2004). "Hilde" and her different classes were followed every week for four months. 


\section{RESULTS}

In order to provide some concrete references for the findings, one vignette from the case study observation sessions will be described involving "Hilde" with a full class of pupils in grade 8 (ages 13-14).

"Hilde": "Circle! Girls on one side and boys on the other!" "Hilde" demonstrates with her arms and the pupils form a circle in the center of the room. "Hilde": "One step in this direction and two steps in this direction, 1-2-3-now!" The pupils move. "Off- beat clapping!" "Hilde" demonstrates, the pupils imitate. Some pupils take two sideway steps. "Hilde": "One step, not two!" "Hilde" recites:

"Are you tough?

Yes I'm tough!

Tough enough?

Got my stuff!

So hit me with that rhythm stick!"

The verse is followed by an interval of four beats meant for improvisation ${ }^{l}$

This short verse is performed rhythmically to sound like a rap; it is divided into smaller parts and memorized to the accompaniment of sideway basic steps and off-beat clapping. "Hilde" asks rhythmically (first line); the pupils imitate her. "Hilde" answers (second line); the pupils imitate her. "Hilde" asks and the pupils answer. The pupils ask and "Hilde" answers. The girls ask and the boys answer. The boys ask and the girls answer. This is repeated several times. After a while, the circle is restructured into two parallel rows with the girls in one row and the boys in the other.

"Hilde" demonstrates a new way of clapping, to a hip hop rhythm. This proves to be too difficult to coordinate with the sideway basic steps, and she returns to off-beat clapping again. She repeats this many times so everyone mastering it. Then she finds a djembe and starts accompanying the activity with the complex hip hop rhythm while the pupils continue practicing off-beat clapping. "Hilde" now fills the four-beat interval with an improvised djembe-break. Everything is repeated from the start and "Hilde" improvises a new djembe-break - and then one more.

A djembe and a chair are placed in the upper end between the two rows and "Hilde" asks: "Do you dare to answer one by one?" "Jens", usually the least attentive pupil in the class, indicates that he dares. He walks to the end of the row and sits down in front of the djembe. "Jens" answers vocally in the right places, when the class asks him, and he improvises a break on the djembe.

Some pupils stop moving and clapping, and become observers. "Hilde": "You must never stop moving or clapping - it's very important that the accompaniment runs steadily". This seemed to work. After a while everyone dares to answer alone, the boys with a little more sound and "muscles" than the girls, who are more concerned with answering correctly and playing nicely.

"Hilde" tries again to get the class to clap the difficult hip-hop rhythm to her accompaniment on the djembe. This time she reduces the tempo and demonstrates the clap movements slowly, excluding the basic steps to go with it. The pupils are going to clap three beats in this way and then rub their hands three times. "Hilde" divides the total phrase into two parts, practices these with the pupils, and then puts the parts together again. The whole phrase is supported by some vocal

1 Composed by Ole Ekroll and Øyvind Skogly Pedersen, published in Rytmisk musikkpedagogikk i grunnskolen 2000 and in the CD: Kotokaka 2002. See picture 1. For the accompaniment see picture 2. 
rhythm phonetics: "Dung dung bak-geng geng bak". Without the basic steps, everyone is doing fine. It is more difficult coordinating it with the sideway basic steps and returning to normal tempo. However, the pupils concentrate on the task, and after a while the performance is much better.

"Jens", who is the one and only breakdancer in the class, is challenged to dance to the hiphop groove of the class. First a djembe break and then: "Please, go ahead!" This is a challenge that "Jens" is happy to meet! He is skilled at this particular activity, and in this lesson he is suddenly transformed into a cooperative, concentrated and competent pupil trying to do his best, following both the music and the instructions! (Hauge in Olsen \& Stenersen Hovdenak, 2007, 119).

According to "Hilde" the process, the positive development of the pupils, is the overall and most important aim for her teaching. Mastering an instrument and participating in the cooperformance is the tool to achieve this aim. She stresses the fact that it is a public school and that most pupils are not going to become professional musicians. "Hilde" claims that the process of entering into a positive development cycle, in which the pupils acquire a new interest in music, is more important than the actual artistic result there and then.

To be able to experience the subject of music in a positive way, to discover that it is great fun. There is something about the process. For example that "Andreas" suddenly found out that "Yes, that was really fun!" and "Yes, I managed to do it!" And that these girls suddenly changed from looking surly and being difficult and uninterested, to suddenly being all hyped up and saying "This is really a lot of fun! Music is the subject that is the most fun in a way" and "We can manage! - LISTEN! How cool!” and “THERE! We've almost got it now! Yippee!” There is something there... (Hauge in Olsen \& Stenersen Hovdenak, 2007, 116).

For "Hilde", the overall challenge is to ensure that her pupils enjoy the experience of making music together. She thinks it is her responsibility to ensure that the subject music will be experienced in a positive way and that the pupils will discover their own potential. "Hilde" wants her pupils to feel that they are part of a community, and to develop a positive attitude towards themselves and others.

Both interviews and observations confirm that "Hilde" organizes her lessons and implements the plans according to the working methods described and exemplified in subchapter in this article - The core of rhythmic music pedagogy. She is happy to have rhythmic music pedagogy as an effective working strategy. Still, it is always a great challenge to keep the group together; to keep their attention and focus, and keep them from being distracted by pupils who are not concentrating. "Tired" pupils, who are not motivated, very often tend to divert the energy and "infect" the group. Even for experienced teachers such as "Hilde", it is sometimes quite demanding to direct group activities "out on the floor". In the interview she tells that she needs a certain minimum of concentration and willingness to have cooperformance activities. To ensure this, she announces to her pupils that there are alternative ways to work with music. Music listening with literature, theory and written tasks is an alternative way. Which alternative that will dominate depend on the working conditions in the class. This "threat" is normally enough to encourage the classes to try her "rhythmic" alternative and to do their best. In the observation period the second alternative was used only once.

Playing popular music in rock band instrumentation is a frequent activity nowadays in Norwegian schools at grades 9 and 10 (ages 14-16). Classes are normally divided in half to become two bands. According to "Hilde", it is a challenge for the teacher to be given new classes of pupils at grade 9, since they need to have a basic ensemble competence before they can play the band-instruments. In other words, they cannot begin playing instruments immediately, but 
need to acquire some fundamental cooperformance skills.

Yes, they want to go directly to the instrument, but then there will be chaos; (.....) if you want ensemble playing, I think you have to have specific basic skills such as the ability to keep the same beat or pulse. (....) After a while they understand that they have to move (Hauge in Olsen \& Stenersen Hovdenak, 2007, 122).

In the grade 9 classes there were many clever instrumentalists. Thanks to the rhythmicensemble work settings "Hilde" had established, they could display their individual talents within the ensembles. "Hilde" organized concerts where everyone in the classes participated; newcomers played alongside the more experienced "musicians".

Having several pupils with different types of handicaps in the class, as is normal in Norwegian schools, is also a big challenge for the "rhythmic music teacher". "Hilde" had several such pupils in each class. Some of them had concentration problems, while others had more physical handicaps. She also had to deal with some surly looking girls who were not interested at all when they started the year. With these girls she made a girls band, added a skilled female pianist and made a simple arrangement of a very popular hit that they had asked for: Kiss me. "Hilde" was very conscious that she had to adapt to the special needs of these pupils if she should have success. Skills in music theory, arranging and composing as well as pedagogical skills were very useful tools in these situations.

Finding the right material and the right working strategies and being able to adapt these to the actual situation with the actual pupils is therefore crucial. "Hilde"s' most important criteria for choosing material and activity is that it gives opportunities for everybody to cooperform in one way or another. "Hilde" listens to the repertoire interests of the pupils, and sometimes she chooses to adapt an arrangement in which she can combine needs or interests of the group with special needs or interests of individuals.

"Hilde" points to education and working conditions at her school as the most important factors for selection of course content and working methods. She also thinks that the national study plans have some impact on her teaching but since they are very general, and the teacher is given much curricular freedom, they play a minor role in comparison with the two other factors. "Hilde" herself has a long teacher education with long in depth studies in music. She has specialized in teaching rhythmic music. The head master at her school thinks that music is an important subject and is eager to give "Hilde" the best working conditions.

\section{DISCUSSION}

This part of the article features discussion of particular challenges associated with leading samspill or cooperformance in compulsory schools, specifically the following concerns: What are the similarities and differences between cooperformance in RMP and directing other similar types of music performance such as traditional school choirs or orchestras? Why is it important to have cooperformance as an obligatory activity in compulsory schools? What particular qualifications does the music teacher need to have in order to become a good "rhythmic" (or RMP) teacher?

Many of the challenges that the cooperformance teacher has to face are similar to the challenges of the teachers conducting traditional choirs and orchestras. As with choirs and orchestras the teacher needs to have knowledge and skills in the music being performed, and he/ she needs to have skills in directing, instructing and conducting. Both the choir- and orchestra conductor as well as the leader of cooperformance in the classroom needs to have pedagogic skills and leadership skills. It is a basic prerequisite for success that the teacher has a thorough understanding of the distinctive features of the media (the cooperformance, the choir singing or 
the orchestra playing), as well as the group of pupils, in relation to the specific task. What are the distinctive characteristics or properties, and what are the overall aims? What is special for the participants? How does one implement the overall aims or goals in the best possible way? Being a teacher involves being a leader, and directing choirs, orchestras and ensembles involves leadership on various levels. The teacher must be professional and must ask the right questions. What is important; which principles are overarching? What actions should be initiated? The teacher has to be able to evaluate the various strategic alternatives in relation to each other, and make the best choices based on the actual situation and the overall aims.

Live music, existing only "in the moment", here and now, requires that everyone must both want to and be able to perform at the same time - in the same moment. Everyone is mutually dependent on everyone else - then and there. However, there are some important differences. In the traditional choir and orchestra the participants usually have musical notation and usually there are more people to each part. In these smaller ensembles featuring rhythmic grooves, improvisation and composing it is difficult to give musical notation a prominent function, especially in classroom with compulsory music, for it is most effective to learn the music by imitation, which is also mostly true to the traditions from which much "rhythmic" music is derived. The pupils are a mixed group of all categories and can easily lose focus and attention, not only if interpretation of notation is emphasized. The teacher therefore has to memorize all the roles and parts in new arrangements. One student per instrument as is usual in rock bands playing popular music makes the performance more transparent. Including improvisation and composition activities opens up for cultural and social differences. Challenging pupils individually in the group that is independent of race, culture, gender or physical and mental handicaps, can be quite challenging.

Based on the author's experience, it may be a more demanding endeavor to direct ensembles playing by ear in public school than to conduct traditional choirs. The teacher must possess a high degree of pedagogic professionalism and have a broad repertoire of competences and skills - artistic competences as well as leadership and didactical competencies. The pupils are relatively unaware of the collective and individual challenges they will meet and have to handle. In addition to the artistic and cultural challenges, there are also the social challenges associated with being an individual in a group - a society in miniature. The mutual dependence on each participant is so much stronger in the ensemble than in the choir. The ensemble is therefore more vulnerable than the choir or the orchestra; it takes very little to ruin an ensemble session, especially in a classroom setting. On the other hand, it is difficult to find a media more effective in providing social affirmation than a music ensemble that functions well.

In Musikk og identitet (translated: Music and Identity), Even Ruud discusses the importance of being seen and confirmed as a person in the early phases of life. This experience is important for the formation of a self-understanding and identity, perhaps one of the most important dimensions. Music as a store of memories and an identity factor is closely connected to feelings, and being allowed to show what you are able to achieve in a musical setting may be of great importance for personal development. According to Ruud, "Music links us to situations where close relations to others give us the basic confidence necessary to try out and challenge our recently discovered new individuality. At the same time, music gives room for experiencing the ability to master, the ability to trust one's own skills and capacities" (Ruud, 1997, 67 - author's translation).

An investigation made by professor Sylvi Stenersen Hovdenak (2004) among pupils at the lower secondary level in Norwegian compulsory school shows that pupils, in general, miss having more creative activities in school. The pupils are keen to develop knowledge that is more 
closely related to their own interests. The school should be more concerned, therefore, with developing subjective and expressive forms of knowledge, and the pupils' personal development in a more fundamental and broad perspective. More recent investigations confirm this need (Danielsen, Skar \& Skaalvik, 2007; Topland \& Skaalvik, 2010).

The sociologist Ivar Frønes claims that participation in a musical setting can make an important contribution to the development of basic social competence. According to Frønes and Ruud, such competence is necessary if one is to hold one's own or to assert oneself in our complicated, multicultural society (Frønes, 1994; Ruud 1997). The form of RMP ensemble playing described here is a medium that requires the participants to develop a certain ability to decentralize socially; in the course of the activity one inevitably discovers others' positions and perspectives, while "open to the exploration of new identities via creative agency: an artistry of liberated individuality without borders" (Hebert, 2009, 47). Ethnomusicologist John Blacking confirmed this in his statement that ensemble playing has a distinctive potential to make people aware of themselves and their responsibility, and to make visible and signal the values that are fundamental in the community (Blacking, 1990, 28). As one of several points of reference, therefore, music can contribute to the development of identity and self-understanding. In one of the lessons the author heard "Hilde" saying: You must listen to "Andreas" - You are going to play together with the hihat. "Andreas" was one of the handicapped pupils who had recently learned to play the drum set.

What particular qualifications does the music teacher need to have in order to become a good "rhythmic" teacher? Being musically and socially "present" in the process - being able to "read" the complex musical and social situation - is a very fundamental skill for the leaders of RMP ensembles. If the leader has good planning procedures, she may come prepared for the problems that are likely to occur and have a strategy for preventing such problems. Handling unexpected problems is a greater challenge, but also it is still possible to be somewhat prepared, having a repertoire of actions and options. Sometimes it is difficult to discover the nature of the problem: is it personal, social, cultural or musical in nature? Some pupils have great concentration problems or other handicaps, which disturb the others. Author experienced "Hilde" being patient with one pupil "Jens", who had severe concentration problems and could "drop out" at any time in the class situations. "Hilde" knew that "Jens" was particularly good with breakdancing. In one lesson (the particular observation described under Results). "Hilde" managed to adapt an arrangement around a Hip Hop groove with the whole class so that "Jens" could improvise a breakdance.

Pupils who are dealing with personal problems are a challenge that comes on top of the musical-didactical problems and contribute to make the situation even more complex. It is to be hoped that the teacher will make the right "diagnosis" of the problems and find a good solution. In Musikkundervisningens didaktikk (translated: Didactics of Teaching Music), Ingrid Maria Hanken and Geir Johansen introduce the concept didactical improvisation to refer to the ability of some experienced teachers to "grasp" the totality and ambiguity surrounding a problem in a complex class situation and instantly solve the problem (Hanken \& Johansen, 1998, 153). They claim that didactical improvisation is "not a logical straight-lined and rational way of making decisions", but rather a "total and intuitive" approach. The term didactic may be confusing for non-Northeuropean readers, since its connotations in English are nearly the opposite of its meaning in Germanic and Scandinavian languages, for which it is a fundamental educational concept that suggests deeply reflective and responsive pedagogy (Kertz-Welzel, 2004). What is important here is the ability to grasp the totality of the situation without relying on evaluation procedures, and to identify a solution at the same time as the problem is discovered. Directing ensemble music requires 
both categories of thinking and experiencing - both the "horizontal" rational way and the more "vertical" intuitive or holistic way of thinking. In order to make good choices "then and there" one must have a good plan, with a clear overall goal and detailed organizational steps based on a philosophy and strategy of teaching and learning. If one is prepared and employs both ways of thinking, one is also ready for the unexpected events, for the surprises and for the problems. And if one is prepared for problems, one is better able to solve them. Research indicates that it may take several years for a teacher to obtain the level of directing skills that "Hilde" demonstrates; this didactical improvisational competence level (Hanken \& Johansen, 1998, 154).

"Hilde" refers to her education as the most important factor for her practice besides the head master of her school who gave her freedom and opportunities. However, to expect that students during their brief music studies at the university should develop such competence fully is not realistic. What one might expect, however, is that they should gain the necessary basic competence, as a platform to work from so that they will at least dare to identify and meet the challenges, and to persevere. In order to provide music teachers with this platform, it is necessary to carry out more serious in-depth studies of RMP within the teacher training. In addition to the very basic training of performance skills in voice, body, percussion, other instruments, improvisation, and ensemble activities by ear, there should also be a more thorough training in directing such activities. The philosophical thinking of RMP is a fundamental prerequisite. In addition, there should be courses organized as modules for those would like to specialize further in the areas of rhythmic music pedagogy.

Today in Norway it is coincidental whether there are courses in RMP or not in music teacher training programs. It depends on who is working in the music departments and their interests. This problem needs to be addressed. Hopefully, the ideas of writers and researchers in this field will be picked up by more music pedagogues and developed further, so that this method gains a more stable and vital place in teacher training and in Scandinavian (particularly Norwegian) compulsory basic school in the coming years.

\section{CONCLUSIONS}

The purpose of this article was to introduce international music educators to the concept of rytmisk musikkpedagogikk (rhythmic music pedagogy, or RMP), a relatively new concept and approach in the Scandinavian countries, along with the results from two research studies carried out in the years from 1997 to 2007. These studies appear to have been the first within this field in Scandinavia. Both studies have been presented and discussed in this article, firstly the discussion of the concept and its implications, and secondly, discussion of challenges it entails for the music teacher. The author has tried to be concrete and use many examples in order to clarify the ideas; however, words and notation can never substitute for the real experience of samspill or "cooperformance".

Both research studies confirm the importance of the RMP educational concept, which stresses the idea that music is something people create together in a social context, and not only an object for more or less passive listening. The idea of embodying the music, using voice, body and percussion as basic tools along with different cooperformance and improvisation strategies including whole classes and groups, is the core of rhythmic music pedagogy. These strategies may include techniques and procedures using different kinds of basic steps combined with rhythm phonetics, word rhythms or ostinatos in sound and movement, improvisation frames of different kinds, ideas about using parallel activities before roles and parts, and also rotation in these roles and parts before introducing the instruments and making the roles and parts more concrete in a 
collaboratively customized arrangement.

Leading RMP activities or cooperformance within the compulsory school context frame is a demanding endeavor. The teacher must have leadership skills at all levels, not only within the area of music, but a broad array of pedagogical skills are also necessary. The teacher must understand the special task given him/her, the media music, especially the media cooperformance but also the special characteristics of the context and the group of pupils. The teacher must have directing skills, including didactical improvisation and organizing skills as well as artistic skills in instruction, performance, music improvisation, composition and arrangement.

Norwegian society has changed considerably across recent decades. From being a relatively homogenous society (apart from the indigenous Sami who have lived all along in the North, but were largely ignored until recently by educators) in recent years Norway has become a multicultural society including immigrants from all over the world, particularly the Middle East, Africa, and Eastern Europe. Pluralism and the cultural diversity are the new reality, and we have to adapt appropriately to this new situation, also in schools.

The American Roger Mantie and the Canadian Lynn Tucker concludes in their recent article: Publicly funded schools are supposed to serve equally in egalitarian, liberal democracies (Mantie \&Tucker, 2012, 269). They stress the need to develop new alternative ways in the thinking of music education. According to Helena Gaunt and Heidi Westerlund we need to focus more on the challenges of becoming more conscious of the creative and multiple dimensions of social interaction in learning music, not least in the contemporary context of rapid change in the cultural industries and higher education as a whole (Gaunt \& Westerlund, 2012).

What possibilities does higher education as a whole have to develop a more sustainable alternative in music education, to educate music teachers who are capable of meeting pupils from diverse groups and cultures in transformation and of creating and re-creating values in music education? How may we educate young people for a multicultural society, and how may we produce more social justice and inclusion? In order to prepare future music teachers for such a complex and challenging task, we need further research on an array of such innovative pedagogies, especially within the field of music teacher training.

\section{REFERENCES}

Blacking, J. (1990). How musical is man? Seattle: University of Washington.

Campbell, P. S. \& Hebert, D. G. (2011). World Beat. In W. M. Anderson \& P. S. Campbell (Eds.), Multicultural Perspectives in Music Education, 2, 115-125 (3 $3^{\text {rd }}$ ed.). Lanham, MD: Rowman-Littlefield Publishers.

Christensen, B. (1983). Mit motiv. Musikpcedagogik bygget på rytme og improvisation. Copenhagen: Gyldendal Denmark.

Christophersen, C. (2009). Rytmisk musikkundervisning som estetisk praksis - en casestudie. Norwegian Academy of Music, 2. Oslo, Norway.

Danielsen, S. S. Skar \& Skaalvik (2007). De viktige få. Analyse av elevundersøkelsen 2007. Kristiansand: Oxford Research.

Ely, M. et al. (2004). Doing qualitative research. Circles within circles. New York, USA: Routledge Falmer.

Frønes, I. (1994). De likeverdige. Om sosialisering og de jevnaldrendes betydning. Oslo Universitetsforlaget.

Gaunt, H., \& Westerlund, H. (2012). Collaborative learning in higher music education. Oxon Ashgate.

Hagen, A. (1996). Rhythm training. A survey on a basic musical training and its relationship to instrumental and ensemble teaching. In J. O. Traasdal, (Ed.), Rhythmic music education. Jazz-Rock-World music. Copenhagen: Rhythmic Music Conservatory. 
Hanken, I. M. \& Johansen, G. (1998). Musikkundervisningens didaktikk. Norway: Cappelen Akademisk forlag.

Hauge, T. B. (1999). Rytmisk musikkpedagogikk i grunnskolen. Video. Bergen: Fagbokforlaget.

Hauge, T. B. (2007). Gehørbasert samspill i klasserommet - hva kan det innebære? - en casestudie av en musikklærer og hennes praksis. In E. Olsen, H. S. Stenersen (Eds.), Musikk-mulighetenes fag. Bergen: Fagbokforlaget.

Hauge, T. B., \& Christophersen, C. (2000). Rytmisk musikkpedagogikk i grunnskolen. Bergen: Fagbokforlaget.

Hauge, T. B., \& Hungnes, I. (2002). Kotokaka - Rytmisk musikkpedagogikk. CD. Bergen: Fagbokforlaget.

Hebert, D. G. (2009). Musicianship, musical identity, and meaning as embodied practice. In T. A. Regelski and J. T. Gates (Eds.), Music education for changing times: Guiding visions for practice (pp. 39-55). Dordrecht: Springer.

Hedegaard, S. (1995). Trommeleg - et musikpcedagogisk grundlag. Brøndby: Semi-forlaget.

Hull, A. (2006). Drum circle facilitation. Building community through rhythm. USA: Village Music Circles.

Hovdenak Stenersen, S. (2004). Elev i ungdomsskolen: Om ungdom, utdanning og identitet. HiO-report, Number 11. Oslo: Høgskolen i Oslo.

LK06.Kunnskapsløftet. (2006). National curriculum for Knowledge Promotion. Primary and lower secondary education. (Last English edition 2011) Governmental publication, Norway. Retrieved 10.10.2012. http:// www.udir.no/Stottemeny/English/Curriculum-in-English/_english/Curricula-in-English/.

Kertz-Welzel, A. (2004). Didaktik of music: A German concept and its comparison to American music pedagogy. International Journal of Music Education, 22, 277-286.

Kvale, S. (2005). Det kvalitative forskningsintervju. Norway: Gyldendal Norsk Forlag.

Mantie, R., \& Tucker, L. (2012). Pluralism, the right and the good in choirs, orchestras, and bands. International Journal of Music Education, 30 (3), August, 2012, 260-271. London: Sage.

Olsen, E., \& Stenersen Hovdenak, S. (Eds.). (2007). Musikk - mulighetenes fag. Bergen: Fagbokforlaget.

Paynter, J. (1970). Sound and silence: Classroom projects in creative music. Cambridge: Cambridge University Press.

Ruud, E. (1996). Musikk og verdier. Oslo: Universitetsforlaget.

Ruud, E. (1997). Musikk og identitet. Oslo: Universitetsforlaget.

Small, C. (1983a). Performance as ritual. Queens University Papers in Social Anthropology Volume 5, England.

Small, C. (1983b). Treasuring the creative process. Lecture given at Bergen University College in 1983, Bergen, Norway.

Small, C. (2010). Afterword. In R. Wright(Ed.), Sociology and music education (pp. 283-290). Aldershot:Ashgate.

Stortingsmelding, nummer 21, 2007-2008: Samspill - et løft for rytmisk musikk. (2008). Norway: Governmental publication.

Sulsbrück, B. (1999). Congas-Tumbadoras - your basic conga repertoire. From Cuban music and Salsa to Rock, Jazz \& Samba. Herning: The Association of Music teachers in Denmark.

Sundin, B. (1988). Musiken i Människan - Om tradition och förnyelse inom det estetiska områdets pedagogik. Stockholm: Natur och Kultur.

Sundin, B. (1995). Barns musikaliska utveckling. Stockholm: Liber Utbildning.

Topland, B. \& Skaalvik, E. M. (2010). Meninger fra klasserommet. Kristiansand: Oxford Research.

Associate Professor Torunn Bakken Hauge

The Grieg Academy, Faculty of Education

Bergen University College

Address: Landåssvingen 15, 5096, Bergen, Norway

Phone: +47 55585927

E-mail: tbh@hib.no 